\title{
Heróis da luta de libertação nacional e a ideia de nação nos discursos do Presidente da República de Moçambique Armando Guebuza
}

Heroes of the National Liberation Struggle and the Idea of Nation in the Speeches of the President of the Republic of Mozambique, Armando Guebuza

Héros de la lutte pour la libération nationale et $l$

idée de nation dans les discours du Président de la République du Mozambique

Armando Guebuza

Lúcio Dionísio Pitoca Posse

\section{OpenEdition}

Journals

Edição electrónica

URL: http://journals.openedition.org/rccs/10682

DOI: $10.4000 /$ rccs.10682

ISSN: 2182-7435

Editora

Centro de Estudos Sociais da Universidade de Coimbra

Edição impressa

Data de publição: 1 setembro 2020

Paginação: 97-118

ISSN: 0254-1106

Refêrencia eletrónica

Lúcio Dionísio Pitoca Posse, « Heróis da luta de libertação nacional e a ideia de nação nos discursos do Presidente da República de Moçambique Armando Guebuza », Revista Crítica de Ciências Sociais [Online], 122 | 2020, posto online no dia 10 setembro 2020, consultado o 10 dezembro 2020. URL : http://journals.openedition.org/rccs/10682 ; DOI : https://doi.org/10.4000/rccs.10682 


\section{LÚCIO DIONÍSIO PITOCA POSSE}

\section{Heróis da luta de libertação nacional e a ideia de nação nos discursos do Presidente da República de Moçambique Armando Guebuza*}

Este artigo analisa a instrumentalização da figura do herói da luta de libertação de Moçambique - nomeadamente Eduardo Mondlane, Samora Machel, Romão Farinha e Luís Marra - levada a cabo nos discursos de Armando Guebuza durante a sua presidência (2005-2009 e 2010-2014). O texto argumenta que Guebuza recorreu a instrumentalização destas figuras para conquistar a legitimidade junto dos moçambicanos com vista a construir a sua ideia de nação, atendendo ao alcance dos objetivos da sua governação, com destaque para o combate à pobreza, o respeito pela diversidade entre os moçambicanos e a unicidade da nação (enquanto território indivisível). Metodologicamente, o artigo baseia-se na técnica de análise de discurso.

Palavras-chave: análise do discurso; elites políticas; instrumentalismo; Moçambique; movimentos de libertação nacional; nacionalismo.

\section{Introdução}

Em Moçambique, como em outros contextos, a prática de elevação de indivíduos à categoria de herói nacional, seguida da sua instrumentalização, é intrínseca ao processo de construção da nação, desde o período da luta de libertação nacional. E esta instrumentalização é liderada pela elite

\footnotetext{
O presente artigo resulta de parte da dissertação de mestrado do autor em Estudos Africanos com o tema: "A ideia de nação nos discursos políticos do Presidente da República de Moçambique Armando Guebuza (2005-2009 e 2010-2014)", apresentada ao ISCTE-Instituto Universitário de Lisboa, Portugal. Agradecimentos: à Ana Lúcia, a Albert Farré e aos dois revisores anónimos, pelos valiosos comentários (sendo que nenhum tem qualquer responsabilidade em relação ao conteúdo do presente artigo); à Angelica João pelo apoio na disponibilização da biografia de algumas figuras analisadas; e à Filomena Capela por ter realizado uma primeira revisão linguística do texto.
} 
política ${ }^{1}$ detentora do poder do Estado, para construir a memória coletiva que permite imaginar a nação (Ribeiro, 2005; Garcia, 2008; Israel, 2010; Meneses, 2018).

Mas ao exaltar-se a figura do herói nacional, associa-se concomitantemente essa figura à imagem dessa mesma elite política. Isto é, esta elite, neste processo, procura transmitir a ideia de que os seus membros são legítimos herdeiros e seguidores dos valores e ideais dos heróis exaltados - ou seja, instrumentalizados - para com isso conquistar a legitimidade que visa liderar o processo de materialização das suas agendas, das quais enfatizo a construção da ideia de nação.

Neste artigo procuro analisar - com recurso à análise de discurso o modo como a figura do herói nacional aparece instrumentalizada nos discursos proferidos por Armando Guebuza enquanto Presidente da República (2005-2014). E simultaneamente mostrar que a instrumentalização - com recurso às ideias de sacrifício, bravura, vitória e união - tinha como objetivo conquistar a legitimidade junto dos moçambicanos, bem como envolvê-los na construção da sua ideia de nação, atendendo ao alcance dos objetivos da sua governação. Neste ponto destaco, por um lado, a massificação da ideia de inclusão por meio do respeito pela diversidade que caracteriza os moçambicanos enquanto nação (coletivo e território indivisível) e, por outro, por meio do combate (coletivo) à pobreza. Para tal, combinei duas dimensões analíticas intrínsecas à análise de discurso: a intratextual e o contexto (van Dijk, 1995, 2006; Macedo et al., 2008; Mazzola, 2009). Esta combinação justifica-se uma vez que, como consideram Macedo et al. (2008: 651), a "análise do discurso não [se limita] [...] unicamente à tomada dos textos produzidos em sua singularidade, mas à compreensão de seu contexto”. Isto é, enquanto a primeira dimensão, intratextual, se concentrou na análise dos aspetos linguísticos e gramaticais, a segunda, o contexto, focou-se nas dinâmicas políticas, sociais e económicas do período de governação de Guebuza.

\footnotetext{
${ }^{1}$ Neste artigo, "elite política" deve ser entendida como um grupo pequeno e relativamente coeso de indivíduos que detém o poder e o exerce sobre a maioria de diferentes formas, nomeadamente por meio da governação do Estado. Mas importa referir que o artigo recorre ao conceito de "elite política" sabendo da dificuldade existente, ao nível do debate teórico, no que toca à sua operacionalização. Esta limitação advém de diferentes fatores, como, por exemplo, as características que permitem que o grupo seja singular em relação aos outros grupos, mesmo com características muito semelhantes. O debate, por exemplo, considera que as características variam em função do contexto, ou seja, que o que é "elite política" em África pode o não ser na Europa ou em outros contextos, por conta da sua génese, dos seus poderes e das funções que desempenha, além de outros atributos que lhes dão forma. O outro aspeto que enforma o debate é a variação na designação do grupo, "classe governante", outras vezes "elite governante" ou "líderes organizados" ou ainda "elite de poder" (Zuckerman, 1977; Farias Filho, 2011; Khan, 2012; Korom, 2015; Best e Higley, 2018; Daloz, 2018).
} 
Não obstantes as diferentes categorias de heróis nacionais, como por exemplo da área cultural e desportiva, enaltecidas por Guebuza nos seus discursos, o artigo tem como objeto a figura dos heróis da luta de libertação nacional, concretamente Eduardo Chivambo Mondlane, Samora Moisés Machel, Romão Fernandes Farinha e Luís Joaquim Marra.

\section{Heróis da luta de libertação nacional e a ideia de nação em Guebuza}

Os heróis nacionais são uma das categorias importantes para se poder edificar a nação, uma vez que pertencem à história coletiva, marcada por um passado de bravura, sacrifício e vitória com o qual a população se pode identificar. Entretanto, é importante ter em atenção que esta categoria - a de herói nacional - é uma construção que procura dar resposta às dinâmicas de edificação da nação. Processo este que é liderado pela elite política detentora do poder do Estado, enquanto instituição responsável pela atribuição do título de herói nacional aos indivíduos (Cainelli, 2004; Ribeiro, 2005; Marschall, 2006; Garcia, 2008).

Mas importa salientar que esta construção é resultado de, pelo menos, dois processos distintos: por um lado, a distorção, que é consequência da seleção e manipulação dos factos para se construir a figura do herói nacional. E, por outro, a fabricação ou mesmo invenção de acontecimentos que possibilitem a criação da imagem do herói (Mazrui, 1963: 23-24). Sendo que ambas são elaborações que têm como objetivo edificar uma figura que sirva de referência para se construir uma nação que responda às dinâmicas internas e externas a si inerentes.

Este processo - o uso da figura de herói nacional na construção da nação - é uma prática observável em diferentes contextos e épocas, como, por exemplo, o caso da África do Sul no período a seguir ao regime do Apartheid, caracterizado pela exaltação de heróis negros no processo de construção da nação (Marschall, 2006); do Brasil, onde a figura do herói aparece destacada nas dinâmicas de construção da nação desde o período da Monarquia até à constituição da República (Cainelli, 2004); e o caso do Quénia, em que a figura de Jomo Kenyatta, enquanto herói nacional, é colocada no centro do processo de edificação da nação queniana (Mazrui, 1963). E Moçambique não é exceção, na medida em que desde o período da luta de libertação nacional que a instrumentalização da figura do herói se mostrou central para a construção da nação moçambicana (Ribeiro, 2005; Garcia, 2008; Barreto, 2011; Basto, 2013).

Guebuza, à semelhança de Samora Machel e Joaquim Chissano, recorreu à figura do herói nacional ao longo dos seus dois mandatos, 2005-2009 e 2010-2014, como Presidente da República, para construir, a partir dos 
discursos, a sua ideia de nação de forma a responder às dinâmicas que caracterizaram o seu período de governação. ${ }^{2}$

De entre as diferentes categorias de herói nacional, observa-se que Guebuza privilegiou, nos seus discursos, os heróis nacionais enquanto produto da luta de libertação nacional, com o objetivo de explorar a memória coletiva dos moçambicanos à volta desta luta para se imaginar a nação. Escolha que reflete a forma com que a Frente de Libertação de Moçambique - FRELIMO ${ }^{3}$ elabora as narrativas sobre a história oficial de Moçambique. Ou seja, de acordo com Souto (2013), a FRELIMO tende a considerar que os combatentes da luta de libertação são os únicos legítimos reivindicadores do processo de construção do Estado que seria responsável pela edificação da nação. Mas mais do que isso, é que estas narrativas tendem a ser construídas e contadas como se a história da FRELIMO fosse a história de Moçambique (Bragança e Depelchin, 1986). Aspetos estes que mostram o modo como as narrativas - que por vezes alimentam a história de Moçambique - tendem a ser excludentes desde o período da luta de libertação nacional (Borges Coelho, 2013; Souto, 2013; Machava, 2015; Meneses, 2015, 2018). ${ }^{4}$

E é neste âmbito que se percebe, mais uma vez, o porquê da instrumentalização - por parte de Guebuza - de figuras como Eduardo Mondlane, fundador e primeiro presidente da FRELIMO; Samora Machel, fundador e segundo presidente da FRELIMO bem como o primeiro Presidente de Moçambique independente; Romão Farinha e Luís Mara, ambos destacados membros da FRELIMO. ${ }^{5}$

Estes heróis nacionais aparecem nos discursos de Guebuza como exemplos concretos de sofrimento e vitória, uma vez que aceitaram sacrificar as suas próprias vidas através da sua entrega na luta de libertação nacional para alcançar a independência:

Trazemos estes exemplos para demonstrar que a nossa Independência só foi possível graças ao sacrifício de homens e mulheres, muitos deles jovens, que se entregaram

\footnotetext{
${ }^{2}$ Perante as outras categorias de heróis nacionais, destacam-se as figuras de José Craveirinha, escritor, Malangatana Valente Ngwenya, artista plástico e escultor e Lurdes Mutola, desportista. ${ }^{3}$ Fundada em junho de 1962. Foi o principal movimento que liderou o processo da luta de libertação nacional (1964-1974). E é desde a proclamação da independência, em 1975, o partido governante em Moçambique.

${ }_{4}^{4}$ Sobre este aspeto, Meneses $(2015,2018)$ mostra - por meio da análise da figura de "xiconhoca" e do "comprometido" - como este processo de exclusão aconteceu ao longo do processo de construção da nação moçambicana.

5 Para além destes heróis Guebuza também conferiu destaque, nos seus discursos, a Josina Machel enquanto referência feminina no processo de construção da sua ideia de nação. A análise à volta da instrumentalização da figura de Josina será feita noutro artigo.
} 
à causa da Libertação da Terra e dos Homens. Muitos dos protagonistas desta Luta abandonaram o conforto das suas famílias, o calor das suas amizades, para correr riscos, incluindo a perda da sua própria vida. (Guebuza, 2006: 60) ${ }^{6}$

É importante destacar dois aspetos nesta citação. Em primeiro lugar, a ideia de libertar, tanto a terra, como os homens, deixando transparecer que os moçambicanos, sobretudo os combatentes, tinham plena consciência de que a liberdade dos moçambicanos estava coartada. E, em segundo lugar, o uso de maiúsculas nos termos "Independência", "Libertação", "Terra", "Homens" e "Luta" significa que Guebuza confere importância a conceitos-chave dos programas nacionalistas na sua associação à vida dos sujeitos elevados a heróis no processo de construção da nação. Estes termos podem servir para caracterizar os nacionalismos, nomeadamente das antigas colónias portuguesas, ${ }^{7}$ na medida em que os movimentos nacionalistas e independentistas reivindicavam a independência e a liberdade tanto sobre a terra como sobre os homens, o que se pode traduzir na reclamação da autonomia, e sendo este um processo levado a cabo por via das armas: a "luta de libertação nacional".

A questão da vontade de libertação, tanto da terra como dos homens, está muito bem explícita no discurso de Guebuza "Cultura moçambicana: esteio da vitalidade, singularidade e futuro da Nação", na cerimónia de abertura do VII Festival Nacional da Cultura, realizado no dia 11 de julho de 2012, ao afirmar o seguinte:

Há cinquenta anos, filhos insignes desta Pátria de Heróis iniciaram o processo de reconstrução da moçambicanidade e do orgulho de terem nascido nesta terra dos seus antepassados. Foi na cultura que a ocupação colonial, através da sua dominação física e simbólica, procurou subjugar, esvaziar, vilipendiar e negar-lhe existência, que essa Geração do 25 de setembro [os combatentes da luta de libertação nacional] foi inspirar-se para sustentar o projeto da libertação da terra dos homens. Foi nas nossas raízes identitárias que nos definimos como um Povo, unido por um propósito, o propósito do resgate da nossa soberania, dignidade e independência. A atribuição de nomes de localidades moçambicanas, de heróis da resistência e de rios às bases da FRELIMO nas Zonas Libertadas, como sejam Chaimite, Quelimane, Zambézia, Nampula, Beira, Ngungunyane e Limpopo visava cultivar e cimentar na consciência

\footnotetext{
${ }^{6}$ Discurso proferido na cerimónia de abertura do ano letivo militar no distrito da Manhiça, província de Maputo, no dia 11 de março de 2005.

7 É o caso da Conferência das Organizações Nacionalistas das Colónias Portuguesas, constituída, em abril de 1961, em Casablanca, pelos movimentos nacionalistas de Moçambique, Angola, Cabo Verde e São Tomé e Príncipe.
} 
dos obreiros da nossa nacionalidade o facto de: Moçambique era de todos nós, estivéssemos onde estivéssemos; que as riquezas, aqui representadas pelos rios, eram riquezas de todos nós, os moçambicanos, estivéssemos onde estivéssemos. (Guebuza, 2013: 85)

Um primeiro aspeto a destacar nesta citação é a ideia de moçambicanidade. A moçambicanidade, como se observa na citação, é a manifestação da identidade nacional, com recurso a vários atributos associados ao território moçambicano. É através desta manifestação que os moçambicanos expressam a sua singularidade na relação com os "não moçambicanos". Sobre este aspeto, João Paulo Borges Coelho (1998) considera que a moçambicanidade reflete a combinação das diversas dinâmicas sociais, económicas, políticas, culturais e outras da história de Moçambique. E de entre as várias dinâmicas, o autor destaca a influência da delimitação de fronteiras na Conferência de Berlim, entre 1884-1885, por ter criado o território que serviu de referência para os diferentes povos nele integrados construírem uma identidade. Neste processo, destaca-se a interação entre quem se identifica como moçambicano, "nós", e os "outros", que podem ser por um lado os colonizadores e, por outro, os diferentes povos vizinhos. Também considera que o processo da luta de libertação nacional é outro dos aspetos presentes na moçambicanidade, uma vez que expressa a unidade entre os moçambicanos e ilustra a singularidade da identidade nacional na sua relação com os colonizadores. Para Borges Coelho, o Acordo Geral de Paz manifesta a moçambicanidade ao simbolizar a (re)união entre os moçambicanos, por via da reconciliação. A reconciliação simboliza o esquecimento ${ }^{8}$ das atrocidades que caracterizaram a guerra entre a Resistência Nacional Moçambicana - RENAMO e o governo da FRELIMO.

E ainda sobre a citação anterior, é de notar que Guebuza procura realçar a ideia de sentimento de pertença à terra, construído com recurso a uma história de origem dos moçambicanos sobre ela. Essa história dá a entender que existe uma ligação antiga entre a terra e os moçambicanos, que pode resumir-se na ideia de ambos se pertencerem, ao ponto de se influenciarem mutuamente ao longo das suas gerações, à semelhança do que diz Anthony D. Smith (1997: 23): “a terra natal torna-se um depósito de memórias e associações históricas, o lugar onde viveram, trabalharam, oraram e lutaram os 'nossos' sábios, santos e heróis".

\footnotetext{
${ }^{8}$ A importância do esquecimento na construção da identidade nacional e a sua respetiva manifestação pode ser resumida nas palavras de Renan (1997 [1882]: 161), "o esquecimento, e mesmo o erro histórico, são um fator essencial na criação de uma nação".
} 
Em relação ao uso da terra no processo de construção da nação, observou-se que durante a governação de Guebuza houve uma alteração da toponímia, principalmente da cidade de Maputo, passando de nomes relacionados com o regime colonial português para nomes relacionados com a língua, a história, entre outros aspetos, dos moçambicanos. Isto pode simbolizar a sua tentativa de reforçar o sentimento de pertença dos moçambicanos à terra na qual se pretende construir a nação moçambicana. ${ }^{9}$

O outro aspeto que a citação anterior permite mostrar é a ideia de nação moçambicana enquanto entidade caracterizada pela diversidade. E para suportar esta ideia, Guebuza recorre à história da luta de libertação nacional, ao considerar que os combatentes desta luta se consideravam um só povo pertencente a uma única terra, manifestada, por um lado, pela união entre eles, e, por outro, pela entrega à luta em qualquer parte de Moçambique. Como está explícito no excerto do seu discurso "Unidade Nacional: génese, afirmação e desafios" na aula magna dirigida aos Cadetes da Academia Militar Samora Moisés Machel, no dia 26 de outubro de 2012:

\begin{abstract}
A Unidade Nacional não é uniformidade de pensamento, comunhão de confissão religiosidade, partilha de orientação política ou unicidade cultural e artística. A Unidade Nacional funda-se e nutre-se na nossa diversidade. A força do compromisso com a nossa História deve residir precisamente aí: somos um povo feito na diversidade, mas que se reencontra na sua História e na sua agenda de cada etapa, que neste momento é a luta contra a Pobreza. Este reencontro produz e reproduz Moçambique como um quadro normativo dentro do qual as nossas diferenças culturais, religiosas, sociais e políticas são confirmadas e renovadas pelo compromisso histórico que funda esta nação e nos enriquecem como um Povo heróico. É dentro deste quadro que essas diferenças interagem, dialogam e reforçam o sentimento de Nação em cada um de nós. (Guebuza, 2013: 420)
\end{abstract}

\footnotetext{
${ }^{9}$ Em relação às alterações na toponímia, a "Rua Marquês de Pombal" passou a designar-se "Rua Ngungunhane”. A "Rua Pereira do Lago" passou a chamar-se "Rua da Frente de Libertação de Moçambique". E para o caso dos distritos municipais, "Distrito Municipal Número 1" passou a designar-se "Distrito Municipal KaMpfumo", "Distrito Número 2" passou a chamar-se "Distrito Municipal Nlhamankulu", "Distrito Número 3" passou a designar-se "Distrito Municipal KaMaxakeni", "Distrito Número 4" passou a ostentar o nome de "Distrito Municipal KaMavota", o "Distrito Número 5" passou para "Distrito Municipal KaMubukwana". No que toca aos Distritos Municipais da "Catembe" e de "Inhaca", só se alterou a grafia, passando a escrever-se "KaTembe" e "KaNyaka", respetivamente. Mas importa referir que esta prática não se iniciou com Guebuza, a mesma vem desde o período da independência, em que o governo da FRELIMO mudou os nomes de avenidas e lugares que ostentavam nomes associados à história de Portugal para nomes relacionados com a luta de libertação nacional, como, por exemplo, Avenida Pinheiro Chagas para Avenida Eduardo Mondlane, Avenida 5 de Outubro para Avenida Josina Machel. Ou ainda a mudança de nome de locais, como foi o caso do Jardim Tunduru, que antes se chamava Jardim Vasco da Gama.
} 


\section{A exaltação de Romão Farinha e Luís Marra}

Com a exaltação de Romão Farinha e Luís Marra, ${ }^{10}$ heróis que têm a região centro e norte de Moçambique como suas terras de origem, pode perceber-se que Guebuza procura obter a legitimidade dos moçambicanos através da elevação e/ou exaltação dos combatentes destas zonas de origem à categoria de herói nacional, uma vez que este ato simboliza o respeito que ele tem por estes combatentes, bem como pelos seus grupos étnico-regionais. Nas palavras de Marschall (2006: 185), este ato permite criar condições para o maior envolvimento das diferentes comunidades (ou seja, grupos étnico-regionais) na construção da sua ideia de nação.

Este ato de Guebuza deve ser entendido no contexto das clivagens étnico-regionais - entre os grupos étnicos da zona sul e os da zona centro e norte de Moçambique - que caracterizam as dinâmicas e processos de construção do Estado, que seria responsável pela construção da nação. E o período da luta de libertação nacional, sobretudo os primeiros anos da formação da FRELIMO, foi o auge desses conflitos. O cerne dessas clivagens - com alguns momentos de violência - concentrava-se no facto de o acesso e o controlo do poder no movimento estar condicionado à filiação étnica, em que os indivíduos dos grupos étnicos das regiões centro e norte acusavam os indivíduos dos grupos étnicos do sul de os excluírem das posições de liderança em benefício dos seus conterrâneos. ${ }^{11}$

Um dos exemplos, recente, sobre estas dinâmicas é o processo da candidatura de Guebuza para o seu primeiro mandato (2005-2009) como Presidente da República. Durante este processo Guebuza assumiu-se como Macua (grupo etnolinguístico do norte de Moçambique, com maior predominância na província de Nampula), suportando esta identidade no facto de ter nascido na província de Nampula, ignorando concomitantemente a sua identidade Ronga (determinada, em parte, pela origem dos seus progenitores, distrito da Catembe, província de Maputo), que tinha assumido

\footnotetext{
${ }^{10}$ Importa referir que, para além destas figuras, Guebuza exaltou outras nos seus discursos, como por exemplo Robati Carlos, natural do distrito de Nangade, província de Cabo Delgado e Orlando Magumbwa, natural do distrito de Lago, província de Niassa. A escolha das figuras em análise nesta secção foi aleatória, meramente para fins de exemplo. Um outro aspeto a aludir é que existe pouca informação documentada sobre a vida destes heróis nacionais, situação que dificulta a análise das suas biografias na relação com os processos e dinâmicas de construção da nação moçambicana. A tentativa de documentar a vida e obra destes heróis, outrora "desconhecidos", foi uma característica da governação de Guebuza. Este ato de compilar e publicar a biografia destes heróis esteve sob a responsabilidade do ARPAC-Instituto de Investigação Sócio-cultural, uma instituição do governo tutelada pelo Ministério da Cultura e do Turismo.

${ }^{11}$ Para mais detalhes sobre as clivagens étnicas no processo de construção do Estado, que seria responsável pela construção da nação em Moçambique, consultem-se, entre outros, Alpers (1974), Opello Jr. (1975), Brito (1991), Cahen (1994) e Florêncio (2002).
} 
na criação da Associação dos Nativos e Amigos de Maputo (Ngiyana ou Nygana) em princípios da década de 1990. Este posicionamento pode ser entendido como uma resposta a esta clivagem, ao procurar dar a entender que o próximo candidato presidencial da FRELIMO não era do sul de Moçambique, mas sim do norte. ${ }^{12}$

Mas estas clivagens podem ser melhor entendidas se analisarmos a forma como decorreu a eleição do candidato da FRELIMO para as eleições presidências de 2014. Ou por outras palavras, a lista dos candidatos a substituição de Guebuza foi constituída, unicamente, por indivíduos que têm as regiões centro e norte de Moçambique como suas zonas de origem, nomeadamente José Pacheco (Ndau), Alberto Vaquina (Macua), Filipe Nyusi (Maconde), Luísa Diogo (Nyungue) e Aires Aly (Yao). A indicação destes candidatos era justificada - pelo menos ao nível das narrativas à volta das candidaturas - por ter chegado a vez de o país ter um Presidente da República que não fosse do Sul, como se verificava, historicamente, desde a criação da FRELIMO (enquanto movimento que liderou a luta de libertação nacional). E o que se verificou foi, de facto, a eleição de Filipe Nyusi como candidato da FRELIMO para as eleições presidenciais de 2014, da qual saiu vitorioso (2015-2019 e 2020-2024). Ademais, a eleição de Nyusi encontra justificação numa outra narrativa - diretamente associada ao grupo étnico Maconde - segundo a qual era a vez dos Macondes acederem e controlarem o poder do Estado através da eleição de um dos seus membros, particularmente, para as funções de Presidente de República, o que simbolizava o pagamento pelo sacrifício que fizeram no processo da luta de libertação nacional. ${ }^{13}$

\footnotetext{
${ }_{12}$ Talvez seja de referir que esta mudança situacional - no sentido de Widlok (2015) com base na ideia de "social deixis" - da identidade étnica por parte de Armando Guebuza se verificou por meio de suas ações e não do seu discurso, como mostra o processo de sua candidatura ao cargo de Presidente da República.

${ }_{13}$ Mas importa referir que estas clivagens não se restringem à FRELIMO ou à dicotomia Sul e Centro/Norte, também se podem observar em outros contextos e entre grupos étnicos específicos, e que partilham (ou disputam) o sentimento de pertença sobre uma determinada terra, como é o caso entre Ndaus e Senas, ambos da província de Sofala. Tive oportunidade de observar clivagens semelhantes durante o meu trabalho de campo no projeto "Barómetro da Governação Municipal", na cidade da Beira em junho de 2017, entre Ndaus e Senas para o acesso ao poder, bem como aos recursos ao nível do município. Esta clivagem assenta no sentimento de exclusão por parte dos indivíduos do grupo étnico Sena, que consideram ser vítimas dos Ndaus, que se encontram no controlo do poder no município da Beira (Posse, 2019). Sobre as narrativas que procuram explicar as clivagens étnicas para o acesso ao poder do Estado, pode-se consultar, por exemplo, a entrevista a Luís Loforte disponibilizada em https://macua.blogs.com/moambique_para_todos/2015/03/ nyusi-pressionado-para-assumir-a-frelimo.html (consultado a 26.06.2020).
} 
No discurso em homenagem a Romão Farinha, ${ }^{14}$ proferido no dia 23 de abril de 2013, nas cerimónias de celebração do aniversário da sua morte, Guebuza faz uma síntese da biografia deste herói, destacando os seus feitos em três atributos, "autoestima", "patriotismo" e "unidade nacional", como se de uma unidade se tratasse.

Romão Fernandes Farinha é uma referência quando falamos de autoestima, de patriotismo e de Unidade Nacional em Moçambique. Ele deve servir de bússola para os que, dentre nós, nascem com poucas posses e em famílias humildes para não baixarem os braços e deixarem de lutar por um futuro melhor. O exemplo de autoestima de Romão Fernandes Farinha demonstra que podemos todos sonhar mais alto e, se acreditarmos nas nossas capacidades vencer os obstáculos que se colocam à nossa frente. (Guebuza, 2014: 14)

Estes atributos - "autoestima", "patriotismo" e "unidade nacional" - são, para Guebuza, elementos importantes que devem ser apropriados pelos moçambicanos nas suas representações identitárias enquanto coletivo, mas sempre em função de um objetivo em comum: o combate à pobreza. Guebuza procurou, a partir do exemplo de proatividade deste herói, mostrar que se pode erradicar a pobreza em Moçambique, desde que haja compromisso, convidando para isso os moçambicanos a reproduzir o exemplo de vida de Romão Farinha.

A "autoestima" pode ser entendida como um chamamento dos moçambicanos a gostarem de ser moçambicanos, de pertencer ao coletivo. Enquanto o "patriotismo" pode ser interpretado como um apelo aos moçambicanos a desenvolver uma paixão pelo território moçambicano, no sentido de os mesmos sentirem que pertencem ao território e que o território é uma pertença deles. Por último, a "unidade nacional" pode ser entendida na feição da diversidade que caracteriza os moçambicanos, no sentido em que este herói foi alguém que aceitou ir combater com outros moçambicanos pertencentes a diferentes grupos etnolinguísticos noutras regiões de Moçambique. E com isto Guebuza procurou defender, por um lado, a sua ideia de união na diversidade, e, por outro, a existência de conhecimento (por parte deste e de outros heróis da luta de libertação nacional) de que Moçambique é uma entidade una e indivisível.

\footnotetext{
${ }^{14}$ Natural de Muidumbe, província de Cabo Delgado. Ingressou nas fileiras da FRELIMO em 1964. Desempenhou as funções de Chefe Efetivo Provincial da FRELIMO na província do Niassa e Chefe Provincial das Operações na mesma província, onde acabou por falecer em 1973, vítima de doença.
} 
Semelhante instrumentalização observou-se nos discursos de Guebuza em homenagem a Luís Marra, ${ }^{15}$ proferido no distrito de Caia, província de Sofala, no dia 25 de outubro de 2013, alusivo às celebrações dos 40 anos do seu falecimento, ao afirmar o seguinte:

Foi graças à Luta de Libertação Nacional, à clareza e entrega de homens e mulheres do quilate de Luís Joaquim Marra que nasceria, a 25 de junho de 1975, uma nação determinada a fazer a pobreza passar para a história [...]. Foi esta luta de Luís Joaquim Marra e dos seus companheiros de armas que: (i) forjou a Unidade Nacional e a comunhão de destino; (ii) enformou a nossa nacionalidade e (iii) estimulou o orgulho pela nossa história, heróis e feitos. (Guebuza, 2014: 180-181)

Neste excerto, como acontece com os discursos referentes a Romão Farinha, Guebuza exalta a dimensão de sacrifício e proatividade de Joaquim Marra, a ser reproduzida pelos moçambicanos enquanto coletivo e potencial nação a ser edificada sobre um mesmo objetivo, que seria, neste caso, o combate à pobreza e a consolidação da unidade nacional - na feição de território indivisível e habitado por um único povo caracterizado pela diversidade.

\section{A exaltação de Eduardo Mondlane e Samora Machel}

O enaltecimento, por parte de Guebuza, das figuras de Eduardo Mondlane e de Samora Machel no processo de construção da sua ideia de nação, fica claro com a consagração de 2009 como ano de Eduardo Mondlane e 2011 como o ano de Samora Machel. Estes são os únicos heróis nacionais que tiveram reconhecimento a este nível durante a governação de Guebuza. Com a definição destas datas, Guebuza procurou celebrar o aniversário da morte dos dois heróis: em 2009 completaram-se 40 anos do assassinato de Eduardo Mondlane e em 2011 passaram-se 25 anos do desastre aéreo de Mbuzini, que vitimou Samora Machel e a sua comitiva. Por outro lado, dedicou uma coletânea a Samora - o que não aconteceu para o caso de Eduardo Mondlane -, que foi publicada em 2012, com o título A nossa missão: Samora Machel - O líder de quem emanam as aspirações de um povo. ${ }^{16}$ Mas a exaltação das

\footnotetext{
${ }_{15}$ Natural do distrito de Caia, Sofala. Ingressou nas fileiras da FRELIMO em 1967. Desempenhou as funções de Chefe de Secção de Artilharia no 2. ${ }^{\circ}$ Sector, de Comandante Adjunto de Artilharia e de Comandante Sectorial, todas na província de Cabo Delgado. Perdeu a vida em 1973, vítima de emboscada do Exército português.

${ }^{16}$ Esta exaltação da figura de Samora Machel por meio da dedicação de um volume dos seus discursos pode ilustrar que no imaginário de Guebuza estes heróis não se encontram ao mesmo nível. O que é interessante, por se tratar de figuras que nunca foram consensuais no seio da FRELIMO enquanto movimento e partido. Porém, não será possível discutir no presente artigo por que os discursos em análise não fornecem elementos que permitam a discussão. Eduardo Mondlane e Samora Machel são "Changanas", e ambos são originários da província de Gaza, distrito de Mandlakazi (também escrito Manjacaze) e do Posto Administrativo de Chilembene respetivamente.
} 
figuras de Eduardo Mondlane e de Samora Machel não é exclusiva a Guebuza, também foi objeto de instrumentalização por parte dos presidentes Joaquim Chissano e recentemente Filipe Nyusi durante as suas governações. E Samora Machel também instrumentalizou a figura de Eduardo Mondlane. Com estas instrumentalizações, a elite política procura responder aos desafios do contexto em que se encontra, como, por exemplo, conquistar a legitimidade dos moçambicanos para a materialização da sua agenda política e de governação (Ribeiro, 2005; Garcia, 2008; Barreto, 2011; Basto, 2013; Meneses, 2018). ${ }^{17}$

Um dos aspetos que se percebe neste processo de exaltação da figura destes heróis - desde o período da luta de libertação nacional - é a ideia de continuidade, ou seja, que Samora Machel herdou e deu prossecução aos ideais de Eduardo Mondlane (Silva, 1998; Shore, 1999; Sopa, 2001; Sousa, 2008; Dava, 2014; Barbosa, 2018; Meneses, 2018). Como pode ser observado, por exemplo, no discurso de Guebuza na inauguração do monumento em homenagem a Samora Machel, proferido no dia 3 de fevereiro de 2011, ao afirmar o seguinte:

Quando celebramos o Ano Eduardo Chivambo Mondlane, prestamos homenagem ao espírito de Unidade Nacional que ele concebeu e fez efervescer em cada um de nós. Ao longo desse ano, exaltamos igualmente os valores que subscrevemos como um Povo heróico, valores esses que o Presidente Eduardo Mondlane encarnou e incutiu nos obreiros da nossa nacionalidade. O Presidente Samora Machel foi herdeiro, guardião e dinamizador do compromisso do Presidente Eduardo Chivambo Mondlane com a Unidade Nacional e com todos os valores nobres que nos caracterizam como um Povo, um Povo muito especial. (Guebuza, 2012: 21)

Apesar de esta citação estabelecer uma filiação de Samora Machel em Eduardo Mondlane, no sentido de Samora Machel ter herdado os ideais de Eduardo Mondlane, enquanto heróis nacionais que lideraram o nacionalismo moçambicano, não ignora a particularidade que os distingue neste processo. Esta particularidade pode ser observada na distinção que Guebuza estabelece, ao considerar que Eduardo Mondlane é o "Arquiteto da unidade nacional", enquanto Samora Machel é o "Pai da nação moçambicana". "Arquiteto" deve ser entendido como alguém que idealiza algo, mas que nem sempre o operacionaliza, sendo este o sentido em que devemos entender a atribuição deste adjetivo a Eduardo Mondlane - porque foi um dos sujeitos

${ }_{17}$ Porém, a RENAMO reconhece Mondlane como herói enquanto o promotor da "Unidade Nacional”, mas recusa-se a reconhecer Samora, por considerar que as suas políticas e práticas foram um atentado à construção da nação moçambicana (Brito, 2009). Além de a RENAMO "exigir" o reconhecimento e a elevação de algumas figuras suas à categoria de herói nacional (Ribeiro, 2005). 
que liderou o processo de criação de uma ideia de nação moçambicana no âmbito da luta pela construção de um Estado independente que seria responsável pela criação da nação. E "Pai” deve ser entendido como quem dá origem a um ser, tal como Samora Machel fez, ao liderar a fase final da luta de libertação nacional após a morte de Eduardo Mondlane e que culminou na conquista da independência em junho de 1975, possibilitando, através do nacionalismo de Estado, o início do processo de construção da nação moçambicana. ${ }^{18}$

Porém, esta exaltação centrada na continuidade tende a "esquecer" propositadamente - no sentido de Renan (1997 [1882]: 161) na sua reflexão sobre a construção da nação - a existência de contradições (sem com isso representar roturas), entre Eduardo Mondlane e Samora Machel, à volta do pensamento sobre o processo de construção da nação moçambicana. Por outras palavras, não foram figuras consensuais dentro da FRELIMO devido à forma excludente, autoritária e violenta como estavam a liderar o processo. Além de ambos terem sido guiados por posicionamentos distintos em relação à ideologia - sendo Eduardo Mondlane aberto ao marxismo, mas não se definindo como tal, enquanto Samora Machel foi assumidamente marxista - que deveria guiar a luta de libertação nacional, bem como a governação de Moçambique depois de alcançada a independência (Shore, 1999; Cabrita, 2000: 24-28, 46-50, 63-68; Macamo, 2002; Marcum, 2017).

No entanto, no que se refere à figura de Eduardo Mondlane, Guebuza procurou instrumentalizar a ideia de sacrifício - como forma de tentar mobilizar os moçambicanos a combater a pobreza, enquanto objetivo central da sua governação, bem como o respeito pela diversidade que caracteriza os moçambicanos. Este respeito manifesta-se na entrega de Eduardo Mondlane à causa nacional, uma vez que abandonou a vida que tinha nos Estados Unidos da América, como funcionário das Nações Unidas e docente da Universidade de Syracuse em Nova Iorque, para ir viver nas mesmas condições a que os moçambicanos estavam sujeitos pelo colonialismo, com o objetivo de lutar pela libertação: ${ }^{19}$

\footnotetext{
${ }_{18}$ A ideia de Guebuza, de que Samora Machel foi herdeiro dos ideais de Eduardo Mondlane, também está presente no discurso "A nossa missão: o combate contra a pobreza" na cerimónia de tomada de posse para o primeiro mandato de Guebuza como Presidente da República, proferido no dia 2 de Fevereiro de 2005, em que diz: "referimo-nos à obra inspirada na vontade dos nossos antepassados de serem livres e prósperos, uma obra assumida por Eduardo Chivambo Mondlane e criativamente continuada por Samora Moisés Machel" (Guebuza, 2006: 10) e no discurso "Samora Machel: o líder de quem emanam as aspirações de um Povo" (Guebuza, 2012: 25-30), enunciado na cerimónia de inauguração da estátua de Samora Machel, no dia 8 de Dezembro de 2011, na cidade de Nampula. 19 O primeiro excerto foi proferido no dia 20 de fevereiro de 2009 por ocasião do lançamento da Academia de Ciências de Moçambique, na cidade de Maputo, e o segundo foi proferido no dia 10 de julho de 2009 no discurso da cerimónia de abertura do IX Festival Nacional dos Jogos Desportivos Escolares.
} 
Ele renunciou a essas oportunidades [emprego nas Nações Unidas e docente da Universidade de Syracuse em Nova Iorque] para si e para sua família. Ele decidiu regressar à terra que o viu nascer para acender a chama da libertação. Essa chama seria transportada por homens e mulheres valorosos e patriotas retos por todos os quadrantes do nosso Moçambique até à vitória final e à subsequente proclamação da Independência Nacional. (Guebuza, 2010: 100)

Engajemo-nos todos na luta contra a pobreza, a nossa agenda da atualidade, em homenagem ao Arquiteto da Unidade Nacional, este Herói que esta pátria de Heróis gerou [...] como a luta pela nossa libertação da dominação estrangeira, a luta contra a pobreza só poderá triunfar com o engajamento e entrega de todos e de cada um de nós, sempre unidos e inspirados nos ideais do Presidente Eduardo Mondlane. (ibidem: 59)

O próprio Eduardo Mondlane escreve, no seu livro Lutarpor Moçambique, sobre a sua dedicação a Moçambique:

Tentei acompanhar o mais que pude o evoluir da situação em Moçambique, e fiquei cada vez mais convencido, por aquilo que vi e a partir de contactos ocasionais através das Nações Unidas com diplomatas portugueses, que a simples pressão política e agitação não modificariam a posição portuguesa. Em 1961 tive a oportunidade de visitar Moçambique durante as férias, viajando por toda a parte verifiquei com os meus próprios olhos as condições existentes e as mudanças que tinham ou não ocorrido desde a minha partida. Ao regressar, deixei as Nações Unidas para me dedicar totalmente à luta de libertação. (Mondlane, 1995: 100)

A paixão pelo território onde se pretende edificar uma nação é de extrema importância, uma vez que serve de leitmotiv para justificar a sua reivindicação, como aconteceu com os diferentes nacionalismos. Mas para que haja paixão, os nacionalistas devem conseguir construir uma história carregada de sentimento ligado ao seu povo. E Eduardo Mondlane na historiografia do nacionalismo moçambicano é descrito como quem conseguiu construir essa história que conferia aos moçambicanos a legitimidade para reclamar o território como sua pertença. Este aspeto também é explorado por Guebuza no seu discurso na cerimónia de abertura da II Conferência Nacional sobre Cultura, realizada no dia 14 de maio de 2009:20

${ }^{20}$ Sobre a importância do território na construção da nação, Smith (1997: 23-24, 2005: 102) e Oommen (1994: 27) defendem que a existência de nação está dependente da existência do território. Smith considera que o processo de reivindicação do território por parte da população passa pela construção de uma história que associe o território à comunidade como sua terra de origem. 
O Presidente Eduardo Mondlane não criou apenas o sentido de nação Moçambicana, a partir do nosso sentimento e consciência comuns de opressão. Ele teve o dom, a sagacidade e o tato de unir moçambicanos de diferentes grupos étnicos, raças e regiões, que não só não se conheciam como também poderiam ter preconceitos uns sobre os outros, estigmas que a dominação estrangeira implantara e promovera. Por isso ele não criou apenas a Nação Moçambicana como também lhe deu substância, criando um Povo com uma cultura e nos configurou um espaço geográfico. (Guebuza, 2010: 17)

Esta exaltação da unidade entre os moçambicanos com respeito pela diversidade presente neste excerto do discurso de Guebuza pode ser entendida como um ato de instrumentalização da figura de Eduardo Mondlane enquanto símbolo da "unidade nacional" para responder, por um lado, à histórica crise étnico-regional entre os moçambicanos da região centro e norte e os da região sul no acesso ao poder e recursos do Estado. E, por outro, para responder à crise político-militar resultante do impasse nas negociações entre o governo da FRELIMO (sob a liderança de Guebuza) e a RENAMO à volta do pacote eleitoral. ${ }^{21}$ Este segundo aspeto, de certa forma, associou-se, pelo menos a nível do discurso público - no sentido de solidarização com as reivindicações da RENAMO - às narrativas sobre o sentimento de exclusão assente na identidade étnico-regional, tornando-se com isso num risco para a ideia de unidade nacional e consequentemente para a governação de Guebuza.

No entanto, o esforço de Eduardo Mondlane em unir os moçambicanos na sua diversidade é questionado, se não mesmo rejeitado, por Barnabé Ncomo (2003) no seu livro Uria Simango: um homem, uma causa, ao descrever Eduardo Mondlane como um líder tribalista. Ncomo constrói a figura de Eduardo Mondlane na sua relação com Uria Simango - no processo de formação da FRELIMO e da luta de libertação nacional - como alguém que privilegiou os indivíduos pertencentes ao seu grupo étnico em detrimento de outros grupos étnicos, no acesso às posições de liderança dentro do movimento.

À semelhança de Eduardo Mondlane, Guebuza explora a figura de Samora Machel nos seus discursos com o objetivo de construir uma ideia de identidade que lhe permitisse mobilizar os moçambicanos a combater a pobreza. Isto também pode ser observado em dois excertos dos seus discursos. O primeiro, na cerimónia de inauguração do monumento dedicado a Samora Machel, no dia 3 de fevereiro de 2011, ao afirmar que:

\footnotetext{
${ }^{21}$ Essencialmente, esta crise foi caracterizada pela pressão da RENAMO sobre a FRELIMO para despartidarizar o Estado, incluindo os órgãos eleitorais, em particular o Secretariado Técnico de Administração Eleitoral (STAE) e a Comissão Nacional de Eleições (CNE). Para a RENAMO, esta é a principal causa da fraude nos processos eleitorais que acabam por dar vitória à FRELIMO desde as primeiras eleições gerais e municipais.
} 
ao declararmos o Ano Samora Machel, estamos também, e, sobretudo, a cristalizar algo que toca os nossos corações, no contexto da luta que travamos contra a pobreza e pelo nosso bem-estar. Para o sucesso célere na luta contra este flagelo, Moçambique clama por mais homens e mulheres [...] como o Presidente Samora Machel. (Guebuza, 2012: 22)

O segundo, na cerimónia de receção dos chefes de Estado e de governo e outras personalidades nas celebrações do aniversário do acidente de Mbuzini, proferido no dia 19 de outubro de 2011, ao considerar que:

recordar o Presidente Samora Machel em Moçambique é buscar a inspiração, a força e a determinação para prosseguirmos na longa epopeia rumo à nossa libertação da pobreza [...] é reforçarmos a nossa certeza de que a nossa causa de lutar contra a pobreza é justa e, por isso, vai triunfar. (ibidem: 47)

Para além da questão da pobreza, Guebuza faz alusão ao papel de Samora Machel na edificação da sua ideia de nação através da unidade nacional. Mas não esclarece o significado de "unidade nacional", tornando o termo impreciso na sua associação a Samora Machel. Esta imprecisão pode ser demonstrada com um excerto do seu discurso na cerimónia de inauguração da estátua de Samora Machel na cidade de Tete, no dia 10 de novembro de 2011:

Hoje devemos manter a Unidade Nacional e cada um de nós, esteja onde estiver, deve sentir-se como estando em sua própria terra. Os moçambicanos de Cabo Delgado a viver na Zambézia devem sentir-se como estando na sua própria terra, em Moçambique, e nunca se devem sentir como estrangeiros. O Presidente Samora Machel foi um grande defensor da Unidade Nacional. (Guebuza, 2012: 55)

Guebuza, ao contrário da exaltação da "unidade nacional" através da interação entre os moçambicanos na sua diversidade, enaltece o sentimento de pertença que os moçambicanos devem alimentar em relação a Moçambique. É de referir que esta imprecisão por parte de Guebuza pode ser entendida como um ato propositado, uma vez que ele já se posicionou em relação ao significado a atribuir à "unidade nacional", ao considerar ser a manifestação da interação entre os moçambicanos com respeito pela diversidade que os caracteriza. Esta ambiguidade de Guebuza na ideia de "unidade nacional" liga-se ao facto de Samora Machel, durante a sua governação, ter apregoado a ideia de unicidade, que significava "unir todos os moçambicanos, para além das tradições e línguas diversas, requer que na nossa consciência morra a tribo para que nasça a nação" (Machel, 1978: 11), 
tendo, para tal, recorrido a meios coercivos na sua edificação, como por exemplo campos de reeducação. ${ }^{22}$

A ideia de indivisibilidade do território presente no trecho do discurso de Guebuza, acima citado, pode ser entendida como um esforço para responder à crise político-militar entre a RENAMO e o governo da FRELIMO, em que a RENAMO ameaçava dividir o território a partir do rio Save, deixando a região sul de um lado e a região centro e norte do outro, caso o governo não cedesse à pressão para reestruturar os órgãos eleitorais. Situação que se efetivou - também marcada por conflito violento entre as duas partes -, restringindo a circulação dos moçambicanos entre as regiões.

A reivindicação da indivisibilidade do território não é uma característica exclusiva de Guebuza, também é possível encontrá-la em Eduardo Mondlane e Samora Machel no processo de construção da nação, se tivermos em atenção que a luta de libertação nacional reclamou o território de Moçambique - com as fronteiras definidas no âmbito da Conferência de Berlim - enquanto entidade indivisível. Aspeto este que pode ser observado na forma como a FRELIMO ignorou (se não mesmo rejeitou), de um lado, a ideia da independência do planalto de Mueda (Cahen, 1999) e, do outro, recusou a proposta do regime colonial português de conceder somente a independência à região norte de Moçambique (Shore, 1999).

\section{Conclusão}

Este artigo mostra que ao referir-se a estes heróis - Eduardo Mondlane, Samora Machel, Romão Farinha, Luís Marra e outros - Guebuza, mais do que exaltar os seus feitos, procurou associar a sua pessoa à figura destes, no sentido de, por um lado, dar a entender que partilham das mesmas experiências de vida, isto se tivermos em atenção que todos foram combatentes da luta de libertação nacional, e, por outro, e em simultâneo, mostrar que é o legítimo herdeiro e continuador dos ideais dos mesmos. Além disso, com esta exaltação, Guebuza procurou também conquistar a confiança dos moçambicanos que têm as regiões centro e norte de Moçambique como suas terras de origem, numa tentativa de responder ao sentimento de exclusão a que os indivíduos destas regiões se consideram, historicamente, vítimas na sua relação com os indivíduos do Sul, no acesso ao poder, bem como aos recursos do Estado.

${ }_{22}$ Para mais detalhes sobre os campos de reeducação, consultem-se Machava (2015) e o material organizado e disponibilizado no website Mozambique History Net, em http://www.mozambique history.net/reeducation.php (consultado a 24.12.2014). 
Não obstante este esforço, percebe-se que a ideia de nação de Guebuza falhou, se observamos que, por um lado, a ideia de unicidade da nação enquanto território indivisível se mostrava cada vez mais frágil, uma vez que os conflitos e as reivindicações para a divisão de Moçambique se tornavam cada vez mais presentes nos discursos dos moçambicanos, no geral, e, entre os políticos, em particular no partido da RENAMO. E, por outro, apesar de ser difícil tirar conclusões no presente artigo, a diversidade entre os moçambicanos parecia estar fragilizada, na medida em que o discurso dos indivíduos do Centro e Norte à volta do sentimento de exclusão no acesso ao poder e aos recursos do Estado se mostrava mais presente. Situação que podia estar a favorecer o distanciamento entre os moçambicanos (Macaringue, 2000; Forquilha, 2017).

Revisto por Rita Cabral

\section{Referências bibliográficas}

Alpers, Edward A. (1974), "Ethnicity, Politics, and History in Mozambique", Africa Today, 21(4), 39-52.

Barbosa, Pedro Oliveira (2018), "O cinejornal Kuxa Kanema e a imagem de Samora Machel”, Oficina do Historiador, 11(2), 139-158.

Barreto, Isabel (2011), "Independência e criação de heróis nacionais: exemplos de Moçambique”, Revista Contemporânea, 1(1), 203-221.

Basto, Maria-Benedita (2013), "The Writings of the National Anthem in Independent Mozambique: Fictions of the Subject-People", Kronos, 39(1), 185-203.

Best, Heinrich; Higley, John (2018), "The Palgrave Handbook of Political Elites: Introduction", in Heinrich Best; John Higley (orgs.), The Palgrave Handbook of Political Elites. London: Palgrave Macmillan, 1-6.

Borges Coelho, João Paulo (1998), "Um itinerário histórico da moçambicanidade", in Fernando Rosas; Maria Fernanda Rolo (coords.), Língua portuguesa: a herança comum. Lisboa: Pavilhão de Portugal - Expo'98/Assírio \& Alvim, 87-126.

Borges Coelho, João Paulo (2013), "Politics and Contemporary History in Mozambique: A Set of Epistemological Notes”, Kronos, 39(1), 10-19.

Bragança, Aquilo de; Depelchin, Jacques (1986), "Da idealização da FRELIMO à compreensão da história de Moçambique”, Estudos Moçambicanos, 5(6), 29-52.

Brito, Luis Cerqueira de (1991), "Le Frelimo et la construction de l'État national au Mozambique. Le sens de la référence au marxisme (1962-1983)”. Tese de Doutoramento em Anthropologie et sociologie du politique, Université de Paris VIII - Vincennes, Paris, France.

Brito, Luis Cerqueira de (2009), "Discurso político e pobreza em Moçambique: análise de três discursos presidenciais”. Comunicação apresentada na II Conferência Dinâmicas 
da Pobreza e Padrões de Acumulação em Moçambique, 22 a 23 de abril, Instituto de Estudos Sociais e Económicos, Maputo, Moçambique.

Cabrita, João M. (2000), Mozambique: The Tortuous Road to Democracy. New York: Palgrave.

Cahen, Michel (1994), "Mozambique, histoire géopolitique d'un pays sans nation", Lusotopie, 1(1-2), 213-266.

Cahen, Michel (1999), “The Mueda Case and Maconde Political Ethnicity. Some Notes on a Work in Progress", Africana Studia, 2, 29-46.

Cainelli, Marlene (2004), "A construção dos heróis e a memória nacional entre os não letrados”, História \& Ensino, 10, 5-19.

Daloz, Jean-Pascal (2018), "Political Elites in Sub-Saharan Africa", in Heinrich Best; John Higley (orgs.), The Palgrave Handbook of Political Elites. London: Palgrave Macmillan, 241-253.

Dava, Fernando (dir.) (2014), Samora Moisés Machel - História de uma vida dedicada ao povo moçambicano. Maputo: ARPAC - Instituto de Investigação Sócio-Cultural.

Farias Filho, Milton Cordeiro (2011), "Elites políticas regionais: contornos teórico-metodológicos para identificação de grupos políticos”, Revista Brasileira de Ciências Sociais, 26(77), 175-188.

Florêncio, Fernando (2002), "Identidade étnica e práticas políticas entre os vaNdau de Moçambique”, Cadernos de Estudos Africanos, 3, 39-63.

Forquilha, Salvador (2017), "Porquê Moçambique precisa da descentralização? Alguns subsídios para o debate”, Boletim IDeIAS, 94.

Garcia, José Luís Lima (2008), "O mito de Gungunhana na ideologia nacionalista de Moçambique”, in Luís Reis Torgal; Fernando Tavares Pimenta; Julião Soares Sousa (coords.), Comunidades imaginadas: nação e nacionalismos em África. Coimbra: Imprensa da Universidade de Coimbra, 131-147.

Guebuza, Armando Emílio (2006), A nossa missão: o combate contra a pobreza, vol. I. Maputo: CEDIMO - Centro de Documentação e Informação de Moçambique.

Guebuza, Armando Emílio (2010), A nossa missão: unidade nacional-Força motriz do nosso desenvolvimento social e económico, vol. V. Maputo: CEDIMO - Centro de Documentação e Informação de Moçambique.

Guebuza, Armando Emílio (2012), A nossa missão: Samora Machel-O líder de quem emanam as aspirações de um povo, vol. VII. Maputo: CEDIMO - Centro de Documentação e Informação de Moçambique.

Guebuza, Armando Emílio (2013), A nossa missão: a paz como motor do nosso desenvolvimento - celebrando as bodas de porcelana da paz em Moçambique, vol. VIII. Maputo: CEDIMO - Centro de Documentação e Informação de Moçambique.

Guebuza, Armando Emílio (2014), A nossa missão: saúde da mulher e da criança - Um desafio multissectorial que se coloca à escala planetária, vol. IX. Maputo: CEDIMO - Centro de Documentação e Informação de Moçambique.

Israel, Pablo (2010), “The Formulaic Revolution. Song and the 'Popular Memory' of the Mozambican Liberation Struggle”, Cahiers d'études africaines, 50(197), 181-216. 
Khan, Shamus Rahman (2012), “The Sociology of Elites”, Annual Review of Sociology, 38, 361-377.

Korom, Philipp (2015), "Elites: History of the Concept”, in James D. Wright (org.), International Encyclopaedia of the Social \& Behavioral Sciences. Amsterdam: Elsevier, 390-395 [2. ${ }^{a}$ ed.].

Macamo, Elísio (2002), “A transição política em Moçambique”, Centro de Estudos Africanos - Occasional Papers, 4.

Macaringue, José (2000), “Testemunho 2: percepções na cidade da Beira”, in Carlos Serra (org.), Racismo, etnicidade e poder: um estudo em cinco cidades de Moçambique. Maputo: Livraria Universitária da Universidade Eduardo Mondlane, 137-155.

Macedo, Laura Christina; Larocca, Liliana Mulher; Chaves, Maria Marta Nolasco; Mazza, Verônica de Azevedo (2008), "Análise do discurso: uma reflexão para pesquisar em saúde”, Interface-Comunicação, Saúde, Educação, 12(26), 649-657.

Machava, Benedito (2015), "Galo amanheceu em Lourenço Marques: o 7 de Setembro e o verso da descolonização de Moçambique”, Revista Crítica de Ciências Sociais, 106, 53-84. DOI: $10.4000 /$ rccs.5876

Machel, Samora (1978), A educação é tarefa de todos nós. Maputo: s.n.

Marcum, John A. (2017), Conceiving Mozambique. Oakland: Springer.

Marschall, Sabine (2006), “Commemorating 'Struggle Heroes’: Constructing a Genealogy for the New South Africa”, International Journal of Heritage Studies, 12(2), 176-193.

Mazrui, Ali (1963), "On Heroes and Uhuru-Worship”, Transition, 11, 23-28.

Mazzola, Renan Belmonte (2009), "Análise do discurso: um campo de reformulações”, in Nilton Milanez; Janaína de Jesus Santos (orgs.), Análise do discurso: sujeitos, lugares e olhares. São Carlos: Claraluz, 7-16.

Meneses, Maria Paula (2015), "Xiconhoca, o inimigo: narrativas de violência sobre a construção da nação em Moçambique”, Revista Crítica de Ciências Sociais, 106, 9-52. DOI: $10.4000 /$ rccs.5869

Meneses, Maria Paula (2018), “Singing Struggles, Affirming Politics: Mozambique's Revolutionary Songs as Other Ways of Being (in) History", in Sheila Pereira Khan; Maria Paula Meneses; Bjørn Enge Bertelsen (orgs.), Mozambique on the Move: Challenges and Reflections. Bergen: Brill, 254-278. DOI: 10.1163/9789004381100 014

Mondlane, Eduardo (1995), Lutar por Moçambique. Maputo: Nosso Chão.

Ncomo, Barnabé Lucas (2003), Uria Simango: um homem, uma causa. Maputo: Edições Novafrica.

Oommen, T. K. (1994), "Estado, nação e etnia: os laços processuais", Revista Crítica de Ciências Sociais, 39, 3-29.

Opello Jr., Walter C. (1975), "Pluralism and Elite Conflict in an Independence Movement: FRELIMO in the 1960s", Journal of Southern African Studies, 2(1), 66-82. 
Posse, Lúcio Dionísio Pitoca (2019), "Identidades étnicas e governação municipal: algumas notas para a reflexão a partir do caso da Beira”, in Sérgio Chichava (org.), Desafios para Moçambique 2019. Maputo: IESE, 111-128.

Renan, Ernest (1997), "Que é uma nação?", Plural - Revista de Ciências Sociais, 4(1), 154-175. Tradução de Samuel Titan Junior [orig. 1882].

Ribeiro, Fernando Bessa (2005), "A invenção dos heróis: nação, história e discursos de identidade em Moçambique”, Etnografia, IX(2), 257-275.

Shore, Herbert (1999), "Resistência e revolução na vida de Eduardo Mondlane”, Estudos Moçambicanos, 16, 19-59.

Silva, Teresa Cruz e (1998), "The Influence of the Swiss Mission on Eduardo Mondlane (1930-1961)", Journal of Religion in Africa, 28(2), 187-209.

Smith, Anthony D. (1997), A identidade nacional. Lisboa: Gradiva. Traduzido por Cláudio Brito [orig. 1991].

Smith, Anthony D. (2005), “The Genealogy of Nations: An Ethno-Symbolic Approach”, in Atsuko Ichijo; Gordana Uzelac (orgs.), When is Nation: Towards an Understanding of Theories of Nationalism. London: Routledge, 94-112.

Sopa, António (org.) (2001), Samora: homem do povo. Maputo: Maguezo.

Sousa, João Tiago (2008), "Eduardo Mondlane e a luta pela independência de Moçambique”, in Luís Reis Torgal; Fernando Tavares Pimenta; Julião Soares Sousa (coords.), Comunidades imaginadas: nação e nacionalismos em África. Coimbra: Imprensa da Universidade de Coimbra, 149-159.

Souto, Amélia Neves de (2013), "Memory and Identity in the History of Frelimo: Some Research Themes”, Kronos, 39(1), 280-296.

van Dijk, Teun A. (1995), "What is Political Discourse Analysis?", in Jan Blommaert; Chris Bulcaen (orgs.), Political Linguistic. S.1.: John Benjamins Publishing Company, 11-52. van Dijk, Teun A. (2006), "Discourse, Context and Cognition”, Sage, 8(1), 159-177. Widlok, Thomas (2015), "Ethnicity as Social Deixis", in University of Cologne Forum "Ethnicity as a Political Resource" (org.), Ethnicity as a Political Resource: Conceptualizations across Disciplines, Regions, and Periods. Bielefeld: Verlag, 85-96. Zuckerman, Alan (1977), "The Concept 'Political Elite': Lessons from Mosca and Pareto", The Journal of Politics, 39(2), 324-344. 
Artigo recebido a 26.10.2018

Aprovado para publicação a 23.03.2020

\section{Lúcio Dionísio Pitoca Posse}

Instituto de Estudos Sociais e Económicos

Avenida do Zimbabwe, n. ${ }^{\circ}$ 1214, código postal: 1102, Maputo, Moçambique

Contacto: lucioposse@gmail.com

ORCID: https://orcid.org/0000-0003-1752-935X

\section{Heroes of the National Liberation Struggle and the Idea of Nation in the Speeches of the President of the Republic of Mozambique, Armando Guebuza}

This article analyses the instrumentalization of the figure of the hero of the national liberation struggle - namely Eduardo Mondlane, Samora Machel, Romão Farinha and Luís Marra - made by Armando Guebuza in his speeches during his rule (2005-2009 and 2010-2014). With this instrumentalization, Guebuza seeks to gain the legitimacy of Mozambicans in order to lead the construction of his idea of the nation, attempting to achieve the goals of his governance, with emphasis on the fight against poverty, the respect for diversity among Mozambicans and the uniqueness of the nation (as an indivisible territory). In terms of methodology, this article is based on the technique of discourse analysis.

Keywords: discourse analysis; instrumentalism; political elites; Mozambique; national liberation movements; nationalism.

\section{Héros de la lutte pour la libération nationale et l'idée de nation dans les discours du Président de la République du Mozambique Armando Guebuza}

Cet article analyse l'instrumentalisation de la figure des héros de la lutte de libération nationale - à savoir Eduardo Mondlane, Samora Machel, Romão Farinha et Luís Marra - faite par Armando Guebuza dans ses discours, pendant sa présidence (2005-2009 et 2010-2014). Le texte soutient que Guebuza a recouru à l'instrumentalisation de ces figures pour gagner la légitimité parmi les mozambicains dans le but de construire son idée de nation, compte tenu des objectifs de sa gouvernance, en particulier la lutte contre la pauvreté, le respect pour la diversité entre les mozambicains et l'unité de la nation (en tant que territoire indivisible). Méthodologiquement, l'article est basé sur la technique de l'analyse du discours. Mots-clés: analyse du discours; élites politiques; instrumentalisme; Mozambique; mouvements de libération nationale; nationalisme. 